
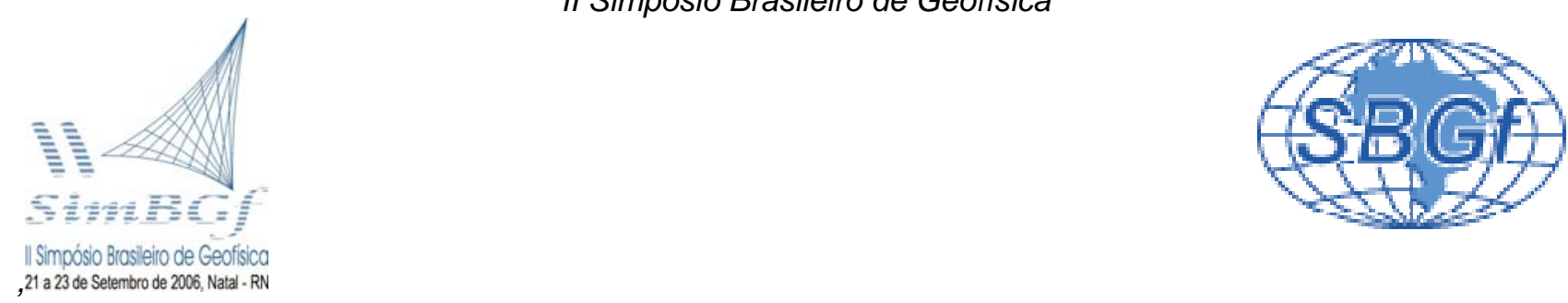

\title{
UTILIZAÇÃO DE IMAGEAMENTO ELÉTRICO 2D E 3D NA IDENTIFICAÇÃO DE LITOFÁCIES PRESENTES NO AQÜÍFERO RIO CLARO, NO CAMPUS DA UNESP
}

Andresa Oliva, Chang Hung Kiang Instituto de Geociências e Ciências Exatas - UNESP.

\section{Resumo}

O modelo de variações de resistividade em subsuperfície, em duas dimensões (2D), é considerado mais preciso que o modelo unidirecional, pois caracteriza mudanças de resistividade tanto na direção horizontal como na vertical, ao longo de uma seção. Já o modelo 3D é considerado o mais preciso, uma vez que todas estruturas geológicas podem ser identificadas tridimensionalmente.

Este trabalho mostra os resultados de um levantamento de imageamento elétrico 2D e 3D realizado no Campus Bela Vista da Unesp de Rio Claro. O arranjo utilizado foi o Dipolo-Dipolo (Dp-Dp), e os resultados obtidos corroboram a capacidade do imageamento em mapear variações de resistividade em duas e três dimensões por meio de um sistema multi-eletrodo.

\section{Introdução}

Dentre as técnicas que se baseiam no método de eletrorresistividade, a da sondagem elétrica vertical (SEV) é a mais utilizada, contemplando investigações verticais de resistividade ao longo de uma dimensão em profundidade.

O imageamento elétrico 2D contempla investigações de variação de resistividade tanto na direção horizontal como na vertical, ao longo de uma seção, de forma automatizada, que utiliza um grande número de eletrodos (25 ou mais) conectados a um cabo multi-eletrodo.

Normalmente, o espaço entre os eletrodos, tanto no imageamento 2D como no 3D, é constante e determinado a partir do objetivo que a pesquisa almeja. O cabo multieletrodo é conectado diretamente ao equipamento ou a uma unidade eletrônica conhecida como switch box.

A distribuição dos eletrodos no imageamento 3D segue normalmente uma malha regular com espaçamento constante. No entanto, já existem programas de inversão de dados de resistividade que permitem a utilização de uma malha irregular (entre linhas ou colunas) de disposição dos eletrodos.

A seqüência de medidas, o tipo de arranjo utilizado e outros parâmetros são normalmente definidos em um programa computacional apropriado, gerando um arquivo que, posteriormente, é lançado ao equipamento.

Com este arquivo, o equipamento se torna apto a selecionar os eletrodos adequados para cada medida. As medidas são armazenadas no equipamento também em forma de arquivo que, por sua vez, retorna ao computador para que possam ser realizadas as interpretações cabíveis. Estes procedimentos são realizados tanto para o imageamento $2 \mathrm{D}$ como para 0 $3 \mathrm{D}$.

A utilização de sistemas multi-eletrodo automatizados viabilizam a execução de levantamentos 3D cobrindo áreas de grandes dimensões que, dependendo do arranjo escolhido, variam de 8 a 20 minutos para aquisição de dados em campo, com sistema de 28 eletrodos.

Trabalhos recentes mostram que sem a utilização de um sistema multi-eletrodo, um ensaio 3D com 25 eletrodos, despende de 3,5 horas (Gandolfo e Gallas, 2004).

Segundo Loke (2001), a técnica da SEV produz de 10 a 20 leituras, enquanto o imageamento 2D produz de 100 a 1000 leituras, e o 3D, em média, milhares de leitura em um tempo relativamente reduzido, com auxílio de sistema multi-eletrodo.

Em muitas situações, o imageamento 2D e/ou 3D pode fornecer resultados complementares às informações obtidas por meio de outras técnicas, ou até mesmo às obtidas por outros métodos geofísicos, eliminando ambigüidades geradas em modelos geoelétricos definidos por uma única técnica.

Tendo em vista esses aspectos, optou-se para a realização do imageamento elétrico 2D e 3D no Campus Bela Vista da Unesp de Rio Claro, localizado no município de Rio Claro - SP, para mapeamento de fácies sedimentares presentes na Formação Rio Claro, que constituem o aqüífero livre Rio Claro. Este levantamento geoelétrico teve o intuito de locação de poço para abastecimento do Campus.

\section{Aquisição e Processamento dos Dados}

O imageamento 2D e 3D, realizado no Campus da Unesp, foi executado com a utilização do equipamento Super Sting R8/IP+28. Este equipamento possui sistema multi-eletrodo (28 eletrodos) (Foto 1). 


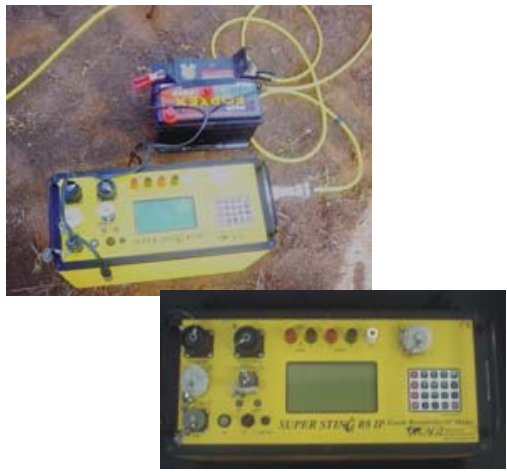

Foto 1 - Resistivímetro Super Sting R8 IP.

Foram realizadas 6 linhas de imageamento elétrico 2D, espaçadas 5 metros entre si (Figura 1).

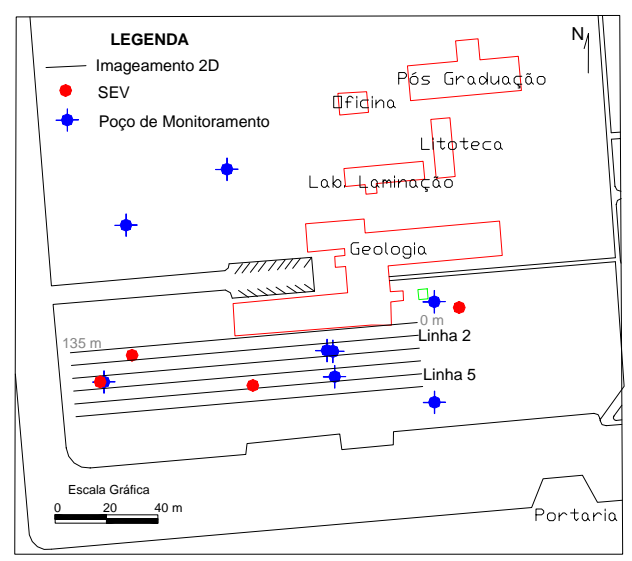

Figura 1 - Local onde foram realizados os ensaios.

Optou-se por uma malha regular entre linhas e colunas para o imageamento 3D (5 x $5 \mathrm{~m})$ (Figura 2).

O critério de escolha do local para execução do ensaio no Campus obedeceu primeiramente à viabilidade para perfuração de um poço e o espaço adequado para a disposição dos eletrodos na malha escolhida.

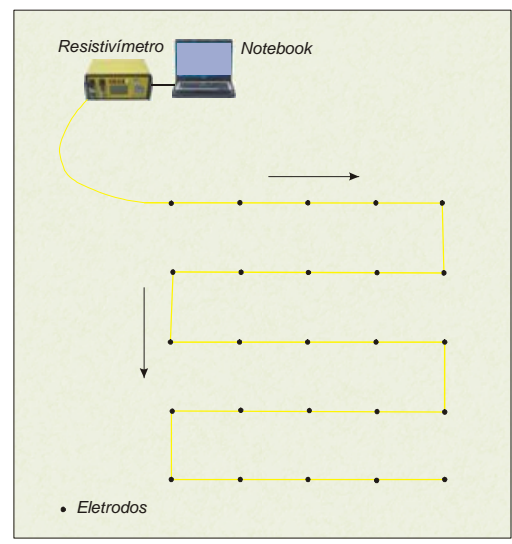

Figura 2 - Desenho esquemático da disposição dos eletrodos no imageamento $3 D$.
Neste trabalho, foram utilizados os arranjos Dp-Dp e Wenner. O arranjo Dp-Dp apresentou resultados mais coerentes quando comparados aos dados preexistentes de SEVs. Este aspecto possivelmente está relacionado à boa convergência dos dados permitida pelo arranjo DpDp.

Com relação ao método de representação de distribuição dos dados de resistividade, o imageamento elétrico 2D é representado por meio de uma pseudo-seção. Vale lembrar que a pseudo-seção é um guia inicial para o estabelecimento de interpretações quantitativas e não uma imagem final da resistividade verdadeira de subsuperfície.

No arranjo Dp-Dp, o método de plotagem mais comum é o de interseção de duas linhas (ponto médio C1-C2 corrente e P1-P2 - potencial) em um ângulo de $45^{\circ}$. É importante enfatizar que esta plotagem é meramente uma convenção, e não implica que a profundidade de investigação seja dada pelo ponto de interseção das duas linhas, com ângulo de $45^{\circ}$.

Praticamente todos sistemas comerciais multi-eletrodos são acompanhados de software para realizar a conversão e a inversão dos dados de resistividade aparente obtidos em campo, gerando seções 2D ou blocos 3D que serão utilizados em interpretações geológicas.

Os programas utilizados nesta pesquisa para inversão dos dados foram: Earthlmager 2D e Earthlmager 3D, produzidos pela $\mathrm{AGI}$ (USA), utilizando o método de inversão "smoothness constrained" (Groot-Hedlin e Contable, 1990).

Essencialmente, todos métodos de inversão tentam reproduzir ao máximo a realidade da subsuperfície onde os dados foram adquiridos.

\section{Resultados}

A Figura 3 apresenta os resultados do levantamento do imageamento elétrico 3D e duas linhas do imageamento 2D, com os dados processados no programa Earthlmager 2D e Earthlmager 3D. Esses softwares permitem a visualização dos valores de resistividade elétrica em seções e blocos. Nos blocos ainda existe a possibilidade de seccionamento em slices nas direções $\mathrm{X}, \mathrm{Y}$ ou Z.

Por meio dos dados de imageamento 2D e 3D, juntamente com os de SEVs e com os de alguns poços de monitoramento existentes nesta área, gerou-se um modelo geoelétrico para a área, correlacionando as resistividades com as litologias.

Inicialmente, identificou-se na Formação Rio Claro dois estratos principais:

- não-saturado, referente à porção localizada acima do nível d’água do aqüífero livre; 
- $\quad$ saturado, referente à porção localizada abaixo do nível d'água, no qual o substrato encontra-se totalmente saturado.

A identificação destas zonas foi efetuada apenas em função da saturação, não levando-se em consideração a litologia (tipo de rocha/sedimento), sendo caracterizada apenas pela determinação do nível d'água, cuja profundidade obtida indicou a separação entre as duas zonas (porções não-saturada e saturada).

Vale ressaltar que a profundidade do nível d’água foi obtida pelas SEVs, pois modelos geoelétricos 3D, em áreas onde não existe homogeneidade dos estratos geológicos, como neste caso, apresentam dificuldade para determinar o NA com precisão, uma vez que levam em consideração as medidas de resistividade do volume (três dimensões), e não pontualmente como a SEV.

A profundidade do nível d’água nesta região varia entre 7,5 e $8 \mathrm{~m}$.

$\mathrm{Na}$ zona saturada (profundidades inferiores a $8 \mathrm{~m}$ ), as seguintes fácies geoelétricas (eletrofácies) foram identificadas:

-predominantemente siltosas $(250<\rho<500$ ohm.m);

-predominantemente arenosas ( $\rho>500$ ohm.m).

O levantamento total abrange um volume de 112.051,3 $\mathrm{m}^{3}$, com predomínio de eletrofácies arenosas $(\rho>500$ ohm.m) na porção centro-oeste e oeste da área do levantamento (Figura $4 \mathrm{~A}$ ). $\mathrm{O}$ volume de sedimentos com resistividade maiores que 500 ohm.m é de 57.605,2 $\mathrm{m}^{3}$.

As eletrofácies siltosas $(250<\rho<500$ ohm.m) ocorrem nos extremos oeste e leste em superfície, mas persistem em profundidade principalmente na porção leste, com volume de $3.213,2 \mathrm{~m}^{3}$ (Figura $4 \mathrm{~B}$ ). Mais a sul, essa camada praticamente desaparece em subsuperfície, aproximadamente no $Y=16,7 \mathrm{~m}$ (linha 5 do 2D).

Dessa forma, com base no imageamento elétrico 2D e $3 \mathrm{D}$, o local mais adequado para perfuração de um poço no aqüífero Rio Claro, nesta área, é a porção centro oeste, onde predominam eletrofácies arenosas.

\section{Conclusões}

Os resultados obtidos nestes ensaios de imageamento elétrico 2D e 3D mostraram a capacidade da técnica em mapear variações de resistividade em planta (eixos $X$ e Y) e em profundidade (eixo Z), podendo ser aplicado não só em identificações de eletrofácies, como neste caso, mas em diversas áreas como, por exemplo, geotecnia e meio ambiente (mapeamento de pluma de contaminação).

Um aspecto relevante nesta técnica, que utiliza um sistema multi-eletrodo, é a agilidade com que os dados são obtidos em campo, pois depois de montado o arranjo o tempo de execução não ultrapassa 20 minutos, dependendo do arranjo escolhido.
Entretanto, o que pôde-se observar é que a técnica mais adequada para delimitar a profundidade do nível d’água (NA) com maior precisão é a da sondagem elétrica vertical.

Já o imageamento 3D contempla medidas de resistividades do volume (três dimensões) e não pontualmente como a SEV, dificultando, em alguns casos, a determinação da profundidade do NA onde os sedimentos não estão dispostos em camadas uniformes.

O que se conclui é que as técnicas de imageamento 2D e/ou 3D são capazes de fornecer resultados complementares às informações obtidas por meio de outras técnicas, ou até mesmo às obtidas por outros métodos geofísicos, eliminando ambigüidades geradas em modelos geoelétricos definidos por uma única técnica. Neste trabalho, auxiliaram na identificação de eletrofácies, com intuito de identificar uma área potencial para perfuração de um poço.

\section{Agradecimentos}

Os autores agradecem ao Laboratório de Estudo de Bacias (LEBAC) por ceder o equipamento de geofísica, e os acessórios necessários para a realização dos ensaios. À Capes pela concessão de bolsa de doutorado e ao CNPq pela bolsa de produtividade.

\section{Referências}

Gandolfo O. C. B., Gallas, J. D. F. 2004. Eletrorresistividade 3D - Resultados Preliminares. (Resumo Expandido do I Simpósio de Geofísica da Sociedade Brasileira de Geofísica).

Groot- Hedlin, C., Constable, S. 1990. Occam's Inversion to Generate Smooth Two-Dimensional Models from Magnetotelluric Data. Geophysics, 55: 1613-1624.

Loke, M. H. 2001. Electrical Imaging Surveys for Environmental and Engineering Studies. A practical Guide to 2D and 3D Surveys, 62p. 


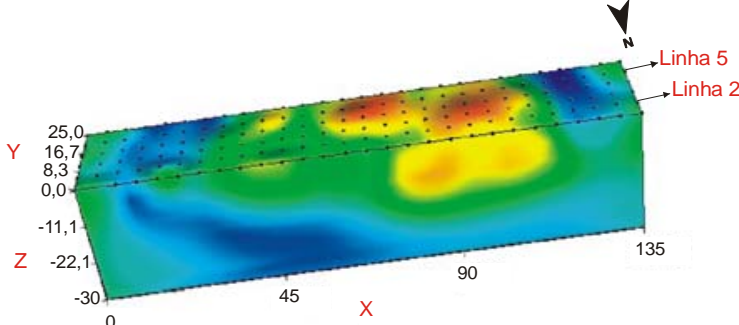

(A)

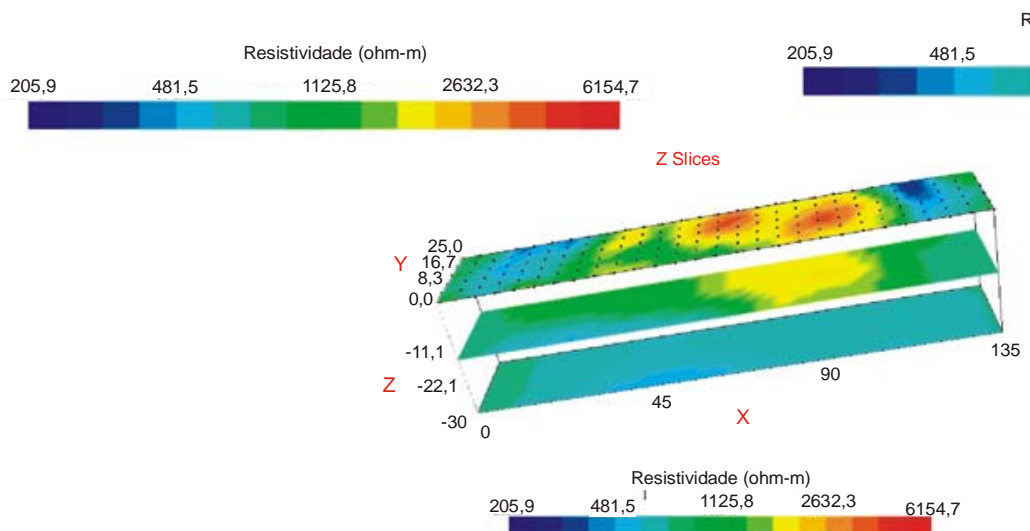

(C)

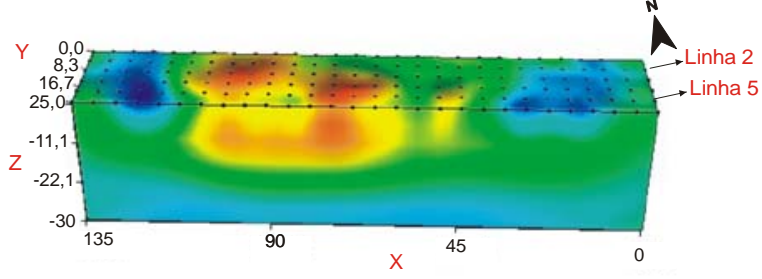

(B)
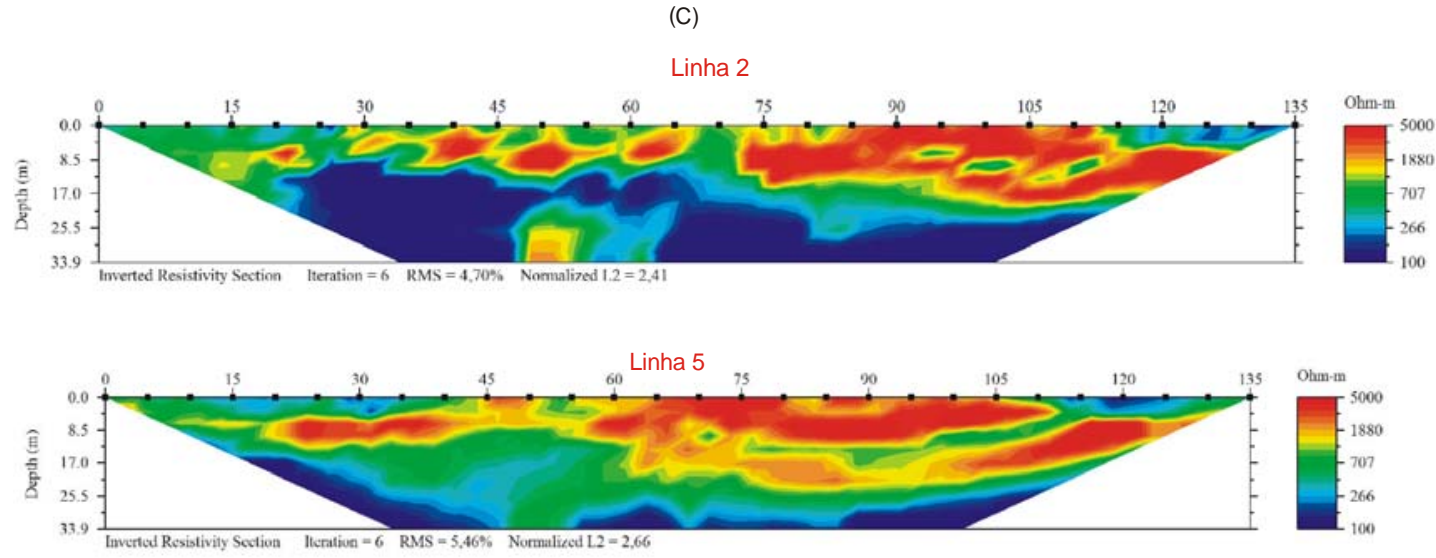

Figura 3 - Modelos de imageamento $3 D$ em imagem frontal (A), detrás (B), seccionamento em slices na direção $Z$ (C) e modelos de imageamento 2D (linhas 2 e 5 ).

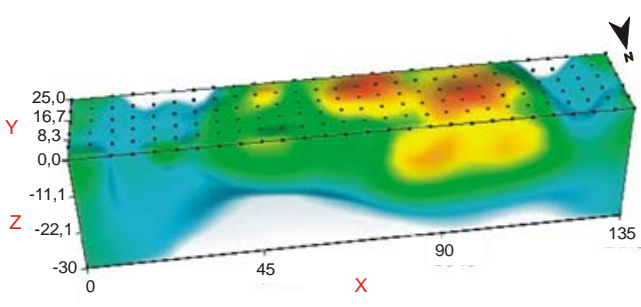

(A)

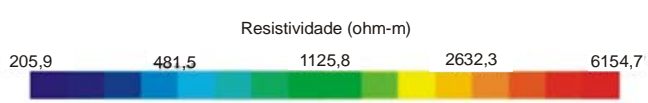

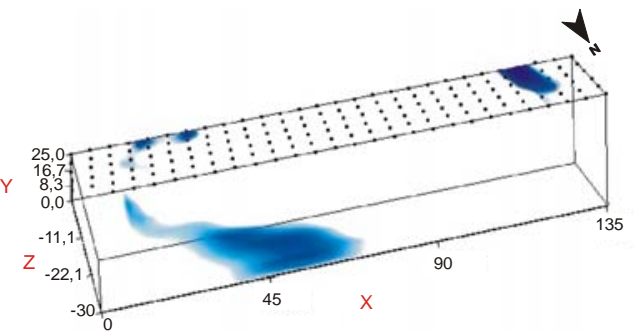

(B)

Figura 4 - (A) Bloco representando as eletrofácies arenosas ( $\rho>500$ ohm.m) e (B) Bloco representando as eletrofácies siltosas $(250<\rho<500$ ohm.m). 